CASE OF

\section{FUNGUS H}

CURED PRINCIPALLY BY LIGATURE.

By Charles Clay, Esq., Surgeon, Manchester, Lecturer on Medical Jurisprudence, \&c.

Hugh Carleton, ætat. 60, of China-lane, Manchester, applied to me for relief under the following circumstances:-Nearly two years ago he was engaged in fixing some iron piping five or six feet from the ground, when the end fell down and struck the nipple of his right breast a severe blow. As the painful sensation was soon over, he thought little of it ; but in a few days a swelling, the size of an egg, appeared, with considerable pain. He applied to a surgeon, who plunged a lancet in it, and a quantity of almost colourless liquid was evacuated ; contrary to expectation, the tumour did not subside, but from that time to the period of his consulting me, it rapidly increased, and when $I$ first saw it, its probable weight was near three pounds, highly vascular over its whole surface, extremely painful, and attended with profuse hamorrhage on the slightest exertion. In consequence of the latter, the patient was reduced to the last stage of debility. The circumference of the tumour round its base was about twelve inches, and at its apex about fifteen, and stood out from the chest at least eight inches. The whole of the upper surface of the mass appeared as full of vessels as a placenta. The constant danger from hæmorrhage rendered it imperatively necessary that something should be done, whilst its situation and vascularity condemned any attempt at extirpation by the knife; for the present I simply applied common dressings of lint, wet with astringent lotion, and advised the patient to be very quiet, being determined to watch the case closely, and act as future circumstances rendered necessary. I was not kept long in suspense; I was hastily called to visit him on the 12th of July last, and found life all but extinct from hæmorthage. I instantly passed a strong ligature round the neck at the base of the tumour, and drew it very tight. I had the greatest possible difficulty in restoring my patient to animation, and for three days he lay in an almost hopeless state, from extreme exhaustion, and the excruciating pain of the ligature. On the 16 th, I passed a second ligature round the base, and afterwards cut away the first. This was attended with great pain, and required powerful opiates to obtain some little mitigation of suffering. My patient now had frequent fits of delirium; his appetite entirely left him, and he appeared rapidly sinking. I felt doubtful as to proceeding, but as the case offered no further prospects on desisting than proceeding, I determined to go on with the ligatures, particularly as the patient in his

No. 947. lucid intervals desired it. I therefore renewed the ligature every third day, and found it was rapidly cutting through the base, leaving a healthy surface behind. From the first application of ligature no hæmorrhage had occurred.

July 27. The parts now uncut by the ligature appeared less vascular than those cut through, and in great apprehension of $\mathrm{my}$ patient sinking from exhaustion, and the severe pain attendant on every new ligature, I concluded to cut it entirely away by the scalpel, which the poor man willingly consented to. A healthy-looking sore now presented itself, which, from the excessive debility prevailing, was extremely slow in healing.

I have now, Sept. 20, dressed it for the last time. No appearance of fungus, and the man is quite well, excepting debility, which is daily giving way to a generous diet and tonic medicines, which is considerably more than I ever anticipated from the severe nature of the case, its situation, and the ad. vanced age of the individual; but it serves to show what perseverance and determination will effect. In this case, the conduct of the patient was beyond all praise; there are few, indeed, who would have suffered so many renewals of agonising pain.

It is more than probable that many cases of this formidable disease might be treated successfully by ligature, as it is my opinion, in many circumscribed cases, the diseased mass is not so deeply connected with the system as to be pronounced hopeless. Few cases bore a worse or more unpromising appearance than the one here quoted, and yet it has been obliterated by local means. In such cases, where frequent hæemorrhage is a prominent feature, I should not hesitate to apply the ligature for a few days; then, when the parts included were sufficiently deadened, I would cut through them. My first intention, in the case here given, was to use a silver wire ligature, with a running noose, that could be tightened daily without removing; but $I$ soon abandoned that idea, because $I$ found it was a ligature for pressure more than cutting that is required for the first few days: when the mass included is sufficiently dead, a silver wire might be used as cutting more freely, but at this stage, to save the patient's suffering, I should prefer the knife. The ligature 1 made use of was a piece of strong greased tape.

\section{PUERPERAL CONVULSIONS.}

\section{To the Editor of The LanceT.}

Sir,-WThe following concise detail of a case in midwifery, accompanied by most violent convulsions, is at your service for publication. I have retired from the general practice of $m y$ profession in consequence of the impaired state of my health. 